\title{
Study on the Influence of Nanosilica Sol on the Hydration Process of Different Kinds of Cement and Mortar Properties
}

\author{
Haibao Liu ${ }^{1}$, Qiuyi $\mathrm{Li}^{2, *}$, Dunlei $\mathrm{Su}^{3, *}{ }^{3}$, Gongbing Yue ${ }^{2}$ and Liang Wang ${ }^{2}$ \\ 1 School of Civil Engineering, Qingdao University of Technology, Qingdao 266033, China; lhbhxw@163.com \\ 2 School of Architectural Engineering, Qingdao Agricultural University, Qingdao 266109, China; \\ yuegongbing@163.com (G.Y.); jiangongwl_2019@163.com (L.W.) \\ 3 School of Civil Engineering, Shandong Jiaotong University, Jinan 250357, China \\ * Correspondence: lqyyxn@163.com (Q.L.); sudunlei@163.com (D.S.)
}

check for updates

Citation: Liu, H.; Li, Q.; Su, D.; Yue, G.; Wang, L. Study on the Influence of Nanosilica Sol on the Hydration Process of Different Kinds of Cement and Mortar Properties. Materials 2021, 14, 3653. https:// doi.org/10.3390/ma14133653

Academic Editor: Diane Rébiscoul

Received: 9 May 2021

Accepted: 24 June 2021

Published: 30 June 2021

Publisher's Note: MDPI stays neutral with regard to jurisdictional claims in published maps and institutional affiliations.

Copyright: (c) 2021 by the authors. Licensee MDPI, Basel, Switzerland. This article is an open access article distributed under the terms and conditions of the Creative Commons Attribution (CC BY) license (https:// creativecommons.org/licenses/by/ $4.0 /)$.
Abstract: Compared with nanosilica collected in a gaseous state, nanosilica sol has great economic value and application significance for improving the performance of concrete and mortar. In this study, the influence of nanosilica sol on the hydration process of different kinds of cement is studied by means of hydration heat analysis, X-ray diffraction analysis (XRD) and other methods, and the properties of mortar such as setting time, mechanical properties and porosity are also studied to characterize the influence of nanosilica sol on the macroscopic properties of mortar. The experimental results show that nanosilica sol can accelerate the hydration rate of two kinds of cement and promote the hydration reaction degree of cement, and this promotion effect increases with the increase in nanosilica sol content. At the same time, nanosilica sol can significantly shorten the setting time of the two kinds of cement, and it is more obvious with the increase in content. Excessive content of nanosilica sol will adversely affect the permeability resistance of mortar. It may be caused by the weak interval formed by nanosilica particle clusters in the mortar matrix, which can be supported by the mortar pore structure distribution test. At the same time, the influence of nanosilica sol on the hydration of the two kinds of cement is different, and the compressive strength of HBSAC cement mortar increases first and then decreases after adding nanosilica sol; However, the compressive strength of P.O 42.5 cement mortar increases gradually after adding nanometer silica sol. This shows that nanosilica sol does not effectively promote the hydration of $\beta-\mathrm{C} 2 \mathrm{~S}$ in high belite sulfoaluminate cement (HBSAC) mortar. Based on the above experimental results, it can be concluded that when the content of nanosilica sol is about $1 \%$, it has the best promotion effect on the hydration of the two kinds of cement and the performance of mortar.

Keywords: nanosilica sol; hydration heat analysis; SEM observation; mechanical strength; chloride penetration resistance

\section{Introduction}

Mineral admixtures have been widely used in concrete for a long time. They can effectively improve the microstructure of concrete and then further affect the mechanical properties and durability of concrete [1-3]. Nanomaterials are considered the most potential materials of the 21st century. At the same time, nanomaterials have also been widely used in concrete. Relevant research shows that compared with commonly used mineral admixtures, nanosilica has a finer particle size, higher pozzolanic activity and a seeding effect [4-14], so the application of nanosilica in concrete has better prospects than other mineral admixtures. Although there have been sufficient studies showing that a lot of benefits can be introduced into cement-based materials by mixing nanosilica, there are still many problems in practical application. When nanosilica is added to cement-based materials, the agglomeration of nanosilica particles will occur. The reason for this phenomenon may be that the production process of nanosilica makes the surface of the particles have huge surface energy, coupled with the high $\mathrm{pH}$ generated after the hydration and dissolution of 
cement and the complex environment containing multiple ions. The nanosilica particles are agglomerated, and this agglomeration phenomenon will damage the performance of concrete and mortar [15-18]. Ghafari et al. [19] showed that the incorrect dispersion of nanosilica will increase the amount of nanosilica in cement-based materials. In addition, nanosilica clusters become harmful pores in cement-based materials after hydration and hardening. The results show that [20] compared with C-S-H gel formed by the hydration of cement, $\mathrm{C}-\mathrm{S}-\mathrm{H}$ gel formed by the reaction of nanosilica clusters and calcium hydroxide $(\mathrm{CH})$ has lower binding performance. At the same time, [21,22] the decrease in mechanical properties of cement-based materials is also due to the poor dispersion of NS in cementbased materials. In addition, after NS particles were aggregated, the number of seeds decreased significantly [23].

Compared with the powdered nanosilica, nanosilica sol has special advantages in particle dispersion. Nanosilica sol can uniformly disperse nanosilica particles in aqueous solution by the hydrolysis of silicon powder, and at the same time, stabilizers such as ammonium chloride are added to the solution so that nanosilica can mostly exist in submicron particle aggregates $[24,25]$ in the solution, thus better exerting crystal nucleation and filling functions. At the same time, many researchers have carried out a series of studies on the influence of nanosilica sol on the properties of cement-based materials. Zhang [26] showed that the particle size of colloidal nanosilica has an influence on the performance of fresh mortar. The results show that when the particle size is $60 \mathrm{~nm}$, nanosilica has the best effect on improving the performance of concrete. Ghasemi et al. [27] showed that colloidal nano- $\mathrm{SiO}_{2}$, as a substitute material for silica fume, can improve the permeability resistance and the compressive strength of concrete. In addition, Kong $[28,29]$ showed that colloidal silica sol has a good effect on cement hydration and concrete microstructure regulation and has more advantages than nanosilica powder.

High-belite sulphoaluminate cement is a kind of green cement $[30,31]$ that consumes less energy and emits less $\mathrm{CO}_{2}$ in the preparation process. At the same time, properties such as quick setting and hardening, low hydration heat and excellent permeability resistance make high-belite sulphoaluminate cement widely useful in many fields, such as road rapid repair. However, high-belite sulphoaluminate cement still has some defects, such as the slow hydration reaction speed of $\mathrm{C}_{2} \mathrm{~S}$, which leads to the insignificant long-term strength growth of cement. Whether the addition of nanosilica sol can improve this shortcoming is a subject worthy of our attention. At the same time, P.O 42.5 cement, as the largest cement variety, has been widely used in construction. By adding nanosilica sol, the different influence laws on the hydration process of the two kinds of cement can be obtained, which has a positive significance for exploring the application of nanosilica sol in different cement-based materials.

Therefore, in this study, hydration heat analysis, X-ray diffraction analysis (XRD), thermogravimetric analysis (TGA) and scanning electron microscope(SEM) observation were mainly conducted to analyze the hydration process of different kinds of cement and the product mineral composition. The influence of nanosilica sol on the macro-micro properties of cement-based materials is revealed.

\section{Experiment}

\subsection{Raw Materials}

In this study, a type of nanosilica sol was obtained from Dezhou Keying New Materials Co., Ltd. (Dezhou, China). High-belite sulphoaluminate cement (HBSAC) was provided by Tangshan Polar Bear Special Cement Co., Ltd. (Tangshan, China). Ordinary Portland cement (P.O 42.5 grade) was by Qingdao Shanshui Cement Co., Ltd. (Qingdao, China). The water-reducing agent from Qingdao New Building Materials Co., Ltd. (Qingdao, China) was used. The main chemical composition of the raw materials by XRF analysis is shown in Table 1. The nanosilica sol was produced by the silica fume hydrolysis method, and the sizes of the nanosilica particles were between 15 and $30 \mathrm{~nm}$. 
Table 1. Chemical composition of the raw materials by XRF (wt.\%).

\begin{tabular}{ccccccccc}
\hline $\begin{array}{c}\text { Chemical } \\
\text { Composition }\end{array}$ & $\mathrm{CaO}$ & $\mathrm{SiO}_{2}$ & $\mathrm{Al}_{2} \mathrm{O}_{3}$ & $\mathrm{Fe}_{2} \mathrm{O}_{3}$ & $\mathrm{SO}_{3}$ & $\mathrm{TiO}_{2}$ & $\mathrm{MgO}$ & $\mathrm{Al}_{2} \mathrm{O}_{3}$ \\
\hline HBSAC & 51.5 & 13.8 & 15.3 & 1.5 & 14.2 & 0.7 & 2.1 & 6.4 \\
P.O 42.5 & 52.7 & 19.9 & 6.4 & 2.8 & 2.6 & 0.4 & $/$ & $/$ \\
\hline
\end{tabular}

\subsection{Design of Experiment}

The addition mixing water and water-reducing agent for mortar is based on the premise of ensuring the same fluidity of each group of test mortar. Referring to the test method of "Sulphoaluminate Cement" (GB 20472-2006, China), the fluidity of each group of test mortar was controlled at $170 \pm 10 \mathrm{~mm}$, and the fluidity of the mortar was adjusted by adding the water-reducing agent. The specific experimental mix proportion design is shown in Table 2. After the raw materials were fully stirred and mixed, the freshly mixed mortar was molded. Then, the demolded pastes were cured at $20 \pm 1{ }^{\circ} \mathrm{C}$ and over $95 \%$ relative humidity for $3 \mathrm{~d}, 7 \mathrm{~d}$ and $28 \mathrm{~d}$. Because the adding order of raw materials of mortar may affect the final form and application effect of nanosilica sol in mortar, in the mortar experiment, each raw material was added in sequence according to the sequence shown in Figure 1. In the mortar mixing test, the adding order of each raw material was cement, nanosilica sol, water and water-reducing agent.

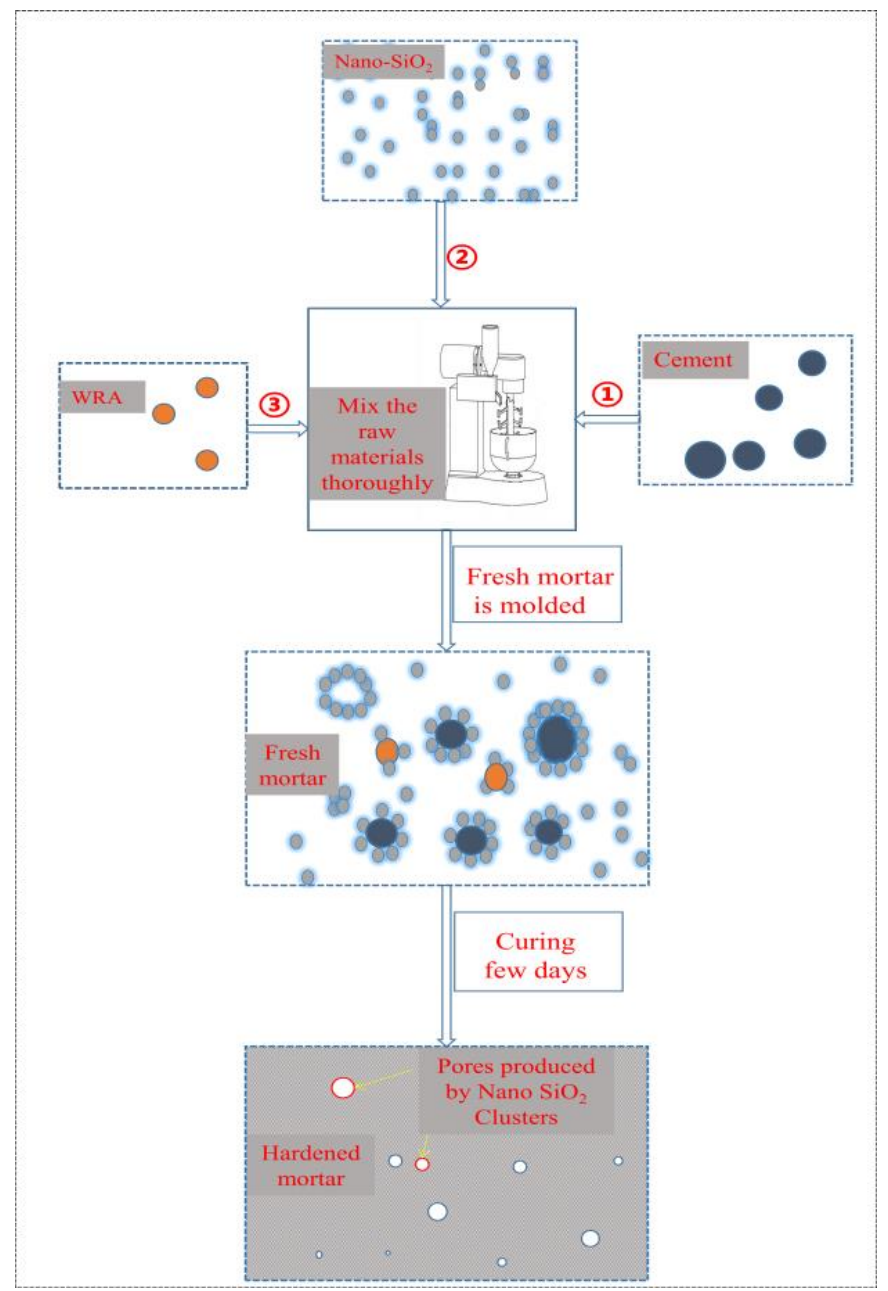

Figure 1. Experimental procedure diagram. 
Table 2. Mix proportion design of mortar.

\begin{tabular}{|c|c|c|c|c|c|c|c|}
\hline Sample & $\begin{array}{c}\text { Nanosilica Sol } \\
\text { Content (\%) }\end{array}$ & $\begin{array}{l}\text { Water-Reducing } \\
\text { Agent }(\%)\end{array}$ & $\begin{array}{c}\text { Fine } \\
\text { Aggregate (g) }\end{array}$ & $\begin{array}{c}\text { Cement } \\
\text { (g) }\end{array}$ & $\begin{array}{l}\text { Water } \\
\text { (g) }\end{array}$ & $\begin{array}{c}\text { Liquidity } \\
\text { (HBSAC) } \\
\text { (mm) }\end{array}$ & $\begin{array}{c}\text { Liquidity } \\
\text { (P.O 42.5) } \\
\text { (mm) }\end{array}$ \\
\hline 1 & 0 & 0 & 1350 & 450 & 180 & 170 & 172 \\
\hline 2 & 0.5 & 0.3 & 1350 & 450 & 180 & 170 & 170 \\
\hline 3 & 1 & 0.6 & 1350 & 450 & 180 & 170 & 173 \\
\hline 4 & 1.5 & 1.0 & 1350 & 450 & 180 & 170 & 171 \\
\hline 5 & 2 & 1.4 & 1350 & 450 & 180 & 170 & 172 \\
\hline
\end{tabular}

\subsection{Experimental Methods}

\subsubsection{SEM Observation}

The influence of nanosilica sol on the microstructure of the different kinds of cement was observed through SEM observation analysis. After the pastes were cured at $20 \pm 1{ }^{\circ} \mathrm{C}$ and over $95 \%$ relative humidity, they could be compared and analyzed through the heat release curve of hydration heat, and the influence of nanosilica sol on the hydration process of cement could be distinguished.

\subsubsection{XRD Analysis}

The mineral composition of cement hydration was detected by using an X-ray diffractometer (D9 Advanced Type, Bruker Co., Karlsruhe, Germany) with relative humidity for 28 days. Then, the testing sample was washed with ethanol, vacuum-dried at $105 \pm 5{ }^{\circ} \mathrm{C}$ for $10 \mathrm{~h}$ and detected by SEM (JSM-7500F type, JEOL Co., Ltd., Tokyo, Japan). The composition and distribution of cement hydration products in specific areas could be analyzed by SEM observation, which provided a more objective basis for the experimental results.

\subsubsection{Hydration Heat Analysis}

The hydration heat test was carried out by using a TAM Air eight-channel microcalorimeter (TAM Air, TA instrument Co. Newcastle, DE, USA), and the operating temperature range of TAM Air was $5-90^{\circ} \mathrm{C}$. The hydration temperature was measured by the adiabatic method. A calorimeter was used to evaluate the effect of nanosilica on the hydration heat of cement paste. Testing samples were prepared at a constant $\mathrm{W} / \mathrm{B}$ ratio of 0.4 , requiring a total of $4 \mathrm{~g}$ of cement samples and $1.6 \mathrm{~g}$ of water. A constant temperature tank used circulating air as the medium, and temperature stability was ensured by an automatic adjustment system. The recording time of the hydration heat of cement samples lasted for $72 \mathrm{~h}$. The influence of different content of nano-silica sol on the hydration process of cement was studied. The working conditions of the machine were: copper target, $45 \mathrm{kV}$ voltage, $50 \mathrm{~mA}$ current, $5^{\circ}-60^{\circ}$ 2-theta scanning range, 0.02 step width and $0.05 \mathrm{~s}$ residence time. A cement paste test specimen with a size of $20 \times 20 \times 20 \mathrm{~mm}^{3}$ was made, and when the test specimen was cured to a specified curing age, the test specimen was ground into a powder to make a sample. XRD analysis can judge the hydration degree of cement and whether the corresponding reaction occurs from the perspective of hydration products so that the experimental conclusion can be objectively supported.

\subsubsection{MIP Analysis}

The type of equipment machine used to test the pore distribution of mortar was an autopore IV 9500 (Micromeritics Co., Atlanta, GA, USA), and the pore size test range was 0.003-1000 $\mathrm{m}$. The size of the test specimen was $1 \times 1 \times 1 \mathrm{~mm}^{3}$. Afterwards, the pastes were cured at $20 \pm 1^{\circ} \mathrm{C}$ and over $95 \%$ relative humidity for 28 days, washed with ethanol and vacuum-dried at $105 \pm 5^{\circ} \mathrm{C}$ for the target age.

\subsubsection{Thermal Analysis}

A comprehensive thermal analyzer (SDT Q600, TA Instruments Co., New Castle, DE, USA) was used for differential thermal analysis of the hydration product. The temperature 
ranged from $20^{\circ} \mathrm{C}$ to $800{ }^{\circ} \mathrm{C}$, the heating rate was $25^{\circ} \mathrm{C} / \mathrm{min}$ and the flow rate was $\mathrm{N} 2$. The hydration product sample was the same as the sample used for XRD analysis.

\subsubsection{Setting Time and Mechanical Properties}

According to the setting time determination method of ordinary Portland cement and high-belite sulphoaluminate cement, referring to the "Test Method for Water Requirement, Setting Time and Stability of Portland Cement Standard Consistency" (GB/T 1346-2011, China), the setting time determination method of ordinary Portland cement and highbelite sulphoaluminate cement was used. The mechanical test method of mortar strength refers to the specification "Sulphoaluminate Cement" (GB 20472-2006, China). The size of the test specimen was $40 \times 40 \times 160 \mathrm{~mm}^{3}$, in which the water demand for mortar mixing was controlled by the fluidity of mortar, and the fluidity was $170 \mathrm{~mm}$. After the mortar test blocks were prepared, all the test specimens were naturally cured for 1 day and then demolded and solidified. Subsequently, it was placed in an environment with a temperature of $20 \pm 1{ }^{\circ} \mathrm{C}$ and relative humidity of no less than $95 \%$ to be cured until target ages. Three samples were used for the setting time test of each group of mortar, and three samples were used for the compressive strength test of each group of mortar at each test age.

\subsubsection{Chloride Penetration Resistance}

The rapid chloride ion migration coefficient method (or $\mathrm{D}_{\mathrm{RCM}}$ method) of "Standard for Test Methods of Long-term Performance and Durability of Ordinary Concrete" (GB/T 50082-2009) as used to evaluate the chloride ion penetration resistance of concrete. The unsteady chloride ion migration coefficient of mortar is calculated by the following formula:

$$
D_{R C M}=\frac{0.0239(273+T) L}{(U-2) t}\left(X_{d}-0.0238 \sqrt{\frac{(273+T) L X_{d}}{U-2}}\right)
$$

In the formula, $U$ represents the absolute value $(\mathrm{V})$ of the voltage used in the test; $T$ represents the average value $\left({ }^{\circ} \mathrm{C}\right)$ of the initial temperature and the end temperature of the anode solution; $L$ represents the thickness $(\mathrm{mm})$ of the test piece; $X_{d}$ represents the chloride ion penetration depth; $t$ represents the duration of the test $(\mathrm{h})$.

\section{Results and Discussions}

\subsection{Hydration Heat Analysis}

The influence of nanosilica sol with different dosages on the hydration heat release rate of cement is shown in Figure 2a,c. It can be clearly seen from Figure 2a that HBSAC cement has two obvious exothermic peaks.

From Figure 2, it can be concluded that the hydration speed and hydration degree of the two kinds of cement are improved to different degrees by adding nanosilica sol. For HBSAC cement, the first exothermic peak is mainly caused by the heat of the hydration heat and dissolution, and the second exothermic peak is mainly caused by hydration in the cement. The second exothermic peak time of HBSAC cement with $0 / 1 \%$ and $2 \%$ nanosilica sol is $1.3 \mathrm{~h}, 1.23 \mathrm{~h}$ and $1.1 \mathrm{~h}$, respectively. Similarly, compared with the control group, when the content of nanosilica sol is $1 \%$, the appearance time of the second and third exothermic peaks of P.O 42.5 can be advanced by $0.2 \mathrm{~h}$ and $0.3 \mathrm{~h}$, respectively. Similarly, when the content of nanosilica sol is $2 \%$, the second and third exothermic peaks of P.O 42.5 cement can be advanced by $1 \mathrm{~h}$ and $2.5 \mathrm{~h}$, respectively. Therefore, the experimental results show that nanosilica can promote the hydration rate of the two kinds of cement, and this phenomenon gradually becomes obvious with the increase in nanosilica content. This phenomenon may be due to the "seeding effect" of nanosilica. Nanosilica sols are fully dispersed in fresh mortar, and those particles can provide seeding sites when cement particles gradually hydrate, which will accelerate cement hydration. At the same time, in order to eliminate the influence of the water-reducing agent on cement hydration, an 
experimental group with the water-reducing agent alone was set up. The test results showed that this water-reducing agent has a retarding effect on the hydration of both cements, and this phenomenon becomes obvious with the increase in water-reducing agent content.
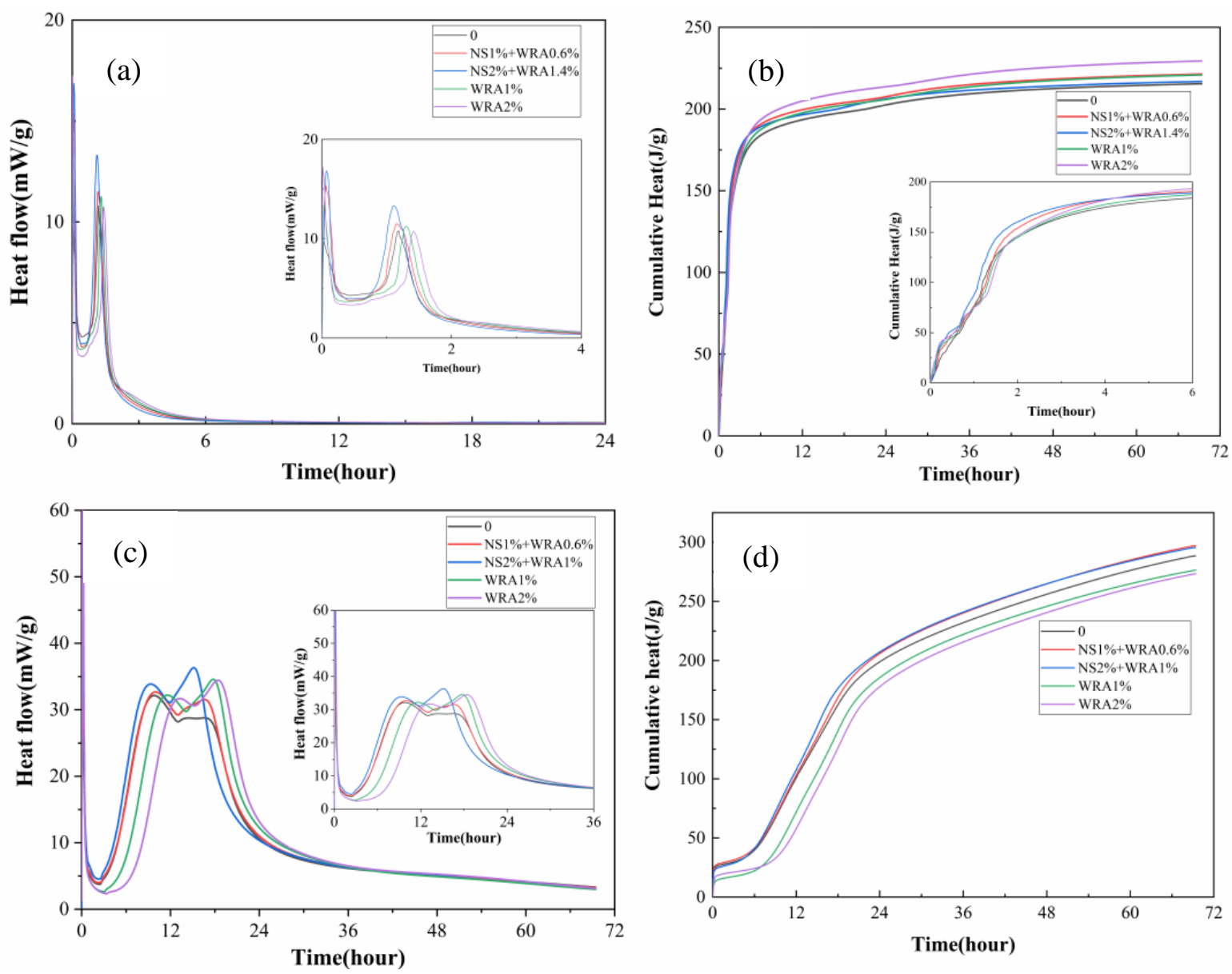

Figure 2. Hydration heat curves of the series cement with nanosilica sol: (a) heat flow curve of HBSAC cement; (b) cumulative heat curve of HBSAC cement; (c) heat flow curve of P.O 42.5 cement; (d) cumulative heat curve of P.O 42.5 cement.

The cumulative heat of hydration of HBSAC cement and P.O 42.5 cement is shown in Figure $2 b, d$, respectively, and Figure 3 shows the growth rate of the cumulative heat of HBSAC cement and P.O 42.5 cement by adding nanosilica sol.

The promotion degree of adding nanosilica to cement hydration can be quantitatively obtained. As can be seen from Figure $3 \mathrm{a}$, the hydration promotion degree of nanosilica sol to HBSAC cement and P.O 42.5 cement reached a peak at $20 \mathrm{~min}$ and $18 \mathrm{~h}$, respectively, and then the promotion degree gradually decreased with the progress of the hydration reaction. Similarly, it is observed from the figure that the degree of promotion for the hydration of the two kinds of cement becomes more significant as the content of nanosilica sol increases. 

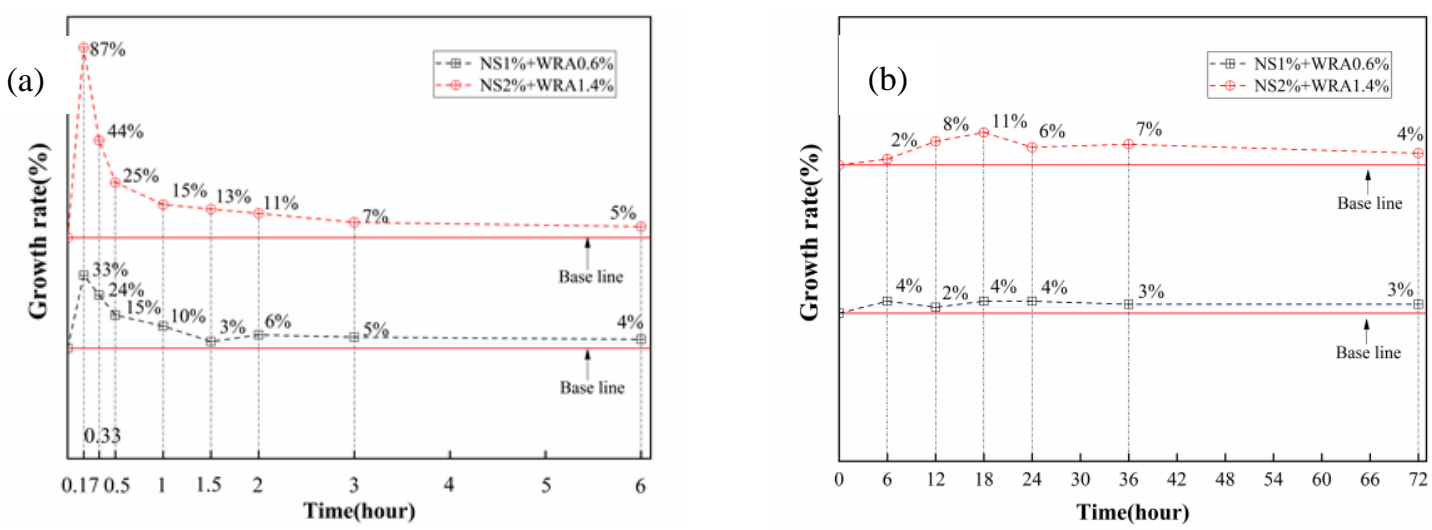

Figure 3. Growth rate of cumulative hydration heat: (a) HBSAC cement; (b) P.O 42.5 cement.

\subsection{Hydration Products Analysis}

\subsubsection{XRD Analysis}

The hydration reaction of P.O 42.5 cement consists of the following reactions:

$$
\begin{gathered}
\mathrm{C}_{3} \mathrm{~S}+3 \mathrm{H} \rightarrow \mathrm{C}-\mathrm{S}-\mathrm{H}(\text { gel })+2 \mathrm{CH} \\
\mathrm{C}_{2} \mathrm{~S}+2 \mathrm{H} \rightarrow \mathrm{C}-\mathrm{S}-\mathrm{H}(\text { gel })+\mathrm{CH}
\end{gathered}
$$

Figure 4 shows that compared with the control group, the peak heights of cement mineral components $C_{3} S$ and $\beta-C_{2} S$ will gradually decrease with the increase in silica content, which means that nanosilica can promote the hydration of $\mathrm{P} \cdot \mathrm{O} 42.5$ cement. At the same time, the peak height of $\mathrm{Ca}(\mathrm{OH})_{2}$, a hydration product of cement, gradually decreases with the increase in silica content. This phenomenon may be caused by the "secondary hydration reaction" $[25,26,32,33]$ between some $\mathrm{Ca}(\mathrm{OH})_{2}$ and nanosilica. The hydrated calcium silicate gel (C-S-H) generated by this reaction will fully fill the pores in the cement paste. This phenomenon has a positive effect on the performance of mortar or concrete.
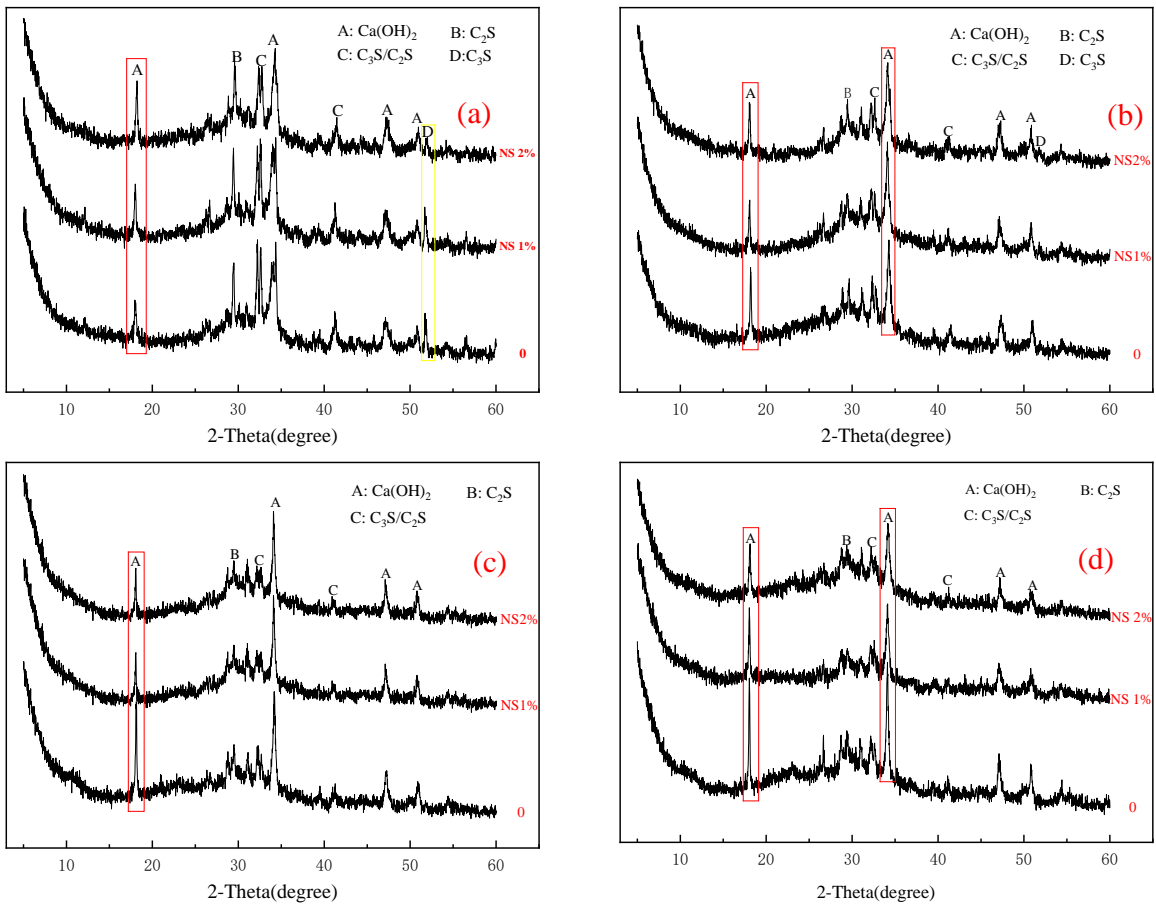

Figure 4. X-ray diffraction (XRD) patterns of the P.O 42.5 cement with different contents of nanosilica sol: (a) 1 day; (b) 3 days; (c) 7 days; (d) 28 days. 
The HBSAC cement hydration reaction consists of the following reactions:

$$
\begin{gathered}
\mathrm{C}_{4} \mathrm{~A}_{3} \overline{\mathrm{S}}+2 \mathrm{C} \overline{\mathrm{S}}+38 \mathrm{H} \rightarrow \mathrm{C}_{3} \mathrm{~A} \cdot 3 \mathrm{C} \overline{\mathrm{S}} \cdot \mathrm{H}_{32}+2 \mathrm{AH}_{3} \\
\mathrm{C}_{2} \mathrm{~S}+2 \mathrm{H} \rightarrow \mathrm{C}-\mathrm{S}-\mathrm{H}(\text { gel })+\mathrm{CH}
\end{gathered}
$$

The hydration rate of anhydrous calcium sulphoaluminate $\left(\mathrm{C}_{4} \mathrm{~A}_{3} \overline{\mathrm{S}}\right)$ is shown in Equation (4), and its hydration rate is extremely fast, which can make the $1 \mathrm{~d}$ strength of high-belite sulphoaluminate cement reach more than $85 \%$ of the final strength $[31,34]$. As can be seen from Figure 5, the content of hydrated calcium sulphoaluminate increases with the increase in nanosilica content at the same cement age, which also indicates that nanosilica can further promote the hydration process of anhydrous calcium sulphoaluminate $\left(\mathrm{C}_{4} \mathrm{~A}_{3} \overline{\mathrm{S}}\right)$. However, the content of $\mathrm{C}_{2} \mathrm{~S}$ does not decrease obviously with the increase in the content of nanosilica sol, which indicates that nanosilica sol has a limited effect on the hydration of $\mathrm{C}_{2} \mathrm{~S}$.
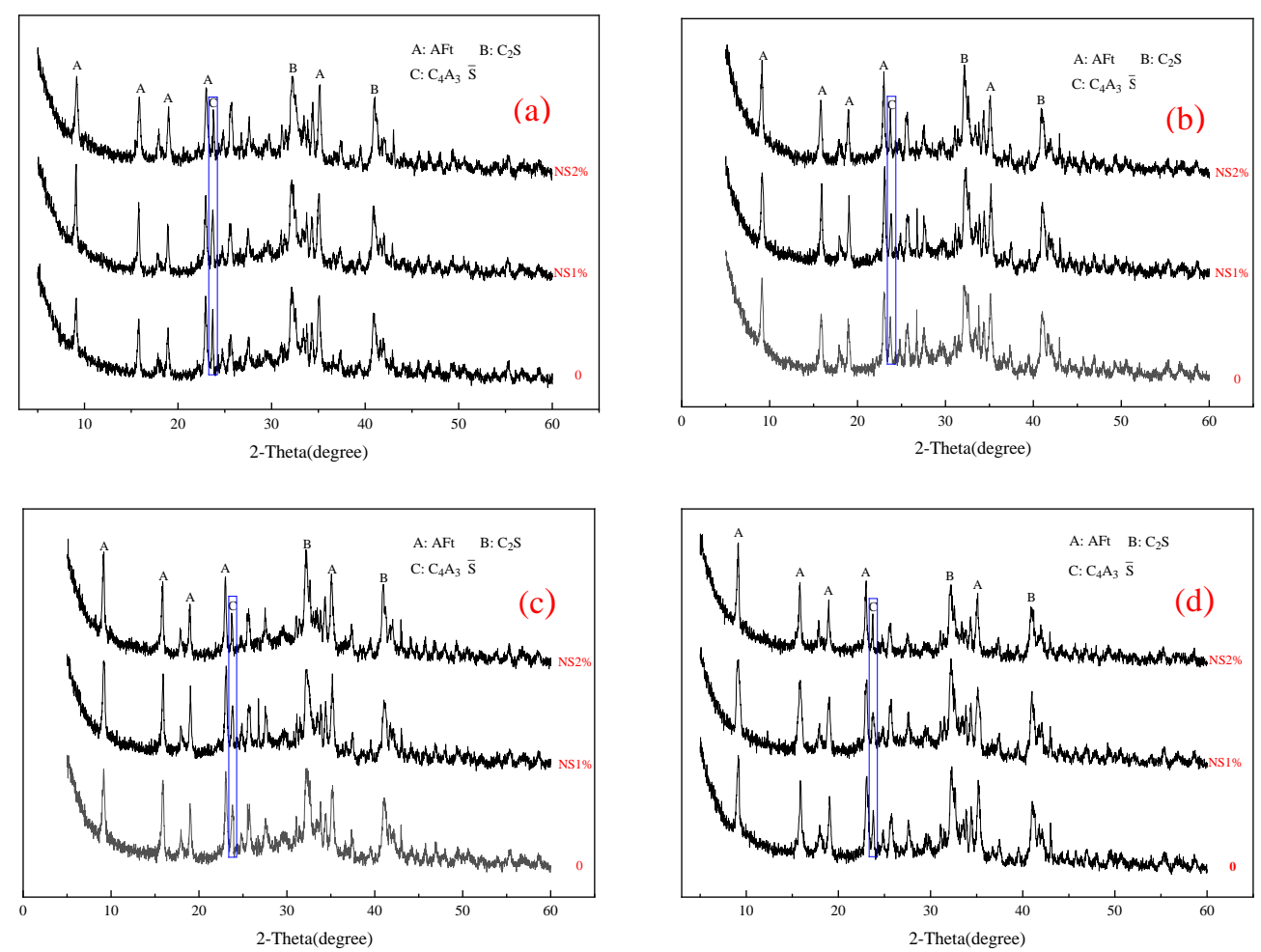

Figure 5. X-ray diffraction (XRD) patterns of the HBSAC cement with different contents of nanosilica sol: (a) 3 h; (b) 6 h; (c) 1 day; (d) 28 days.

\subsubsection{TGA Analysis}

Figure 6 shows the thermogravimetric loss curves of the cement hydration products at different curing ages.

The dehydration decomposition temperature of hydrated calcium sulphoaluminate (AFt), a type of HBSAC hydration product, is generally $100-150{ }^{\circ} \mathrm{C}$. The dehydration decomposition temperature of calcium hydroxide $\left(\mathrm{Ca}(\mathrm{OH})_{2}\right)$ is generally $350-550{ }^{\circ} \mathrm{C}[35,36]$. Calcium hydroxide $\left(\mathrm{Ca}(\mathrm{OH})_{2}\right)$ in the HBSAC cement hydration product is produced by the reaction shown in Equation (5). The experimental results show that there is almost no dehydration decomposition of calcium hydroxide $\left(\mathrm{Ca}(\mathrm{OH})_{2}\right)$ except AFt. However, the hydration degree of $\mathrm{C}_{2} \mathrm{~S}$ did not change obviously with the addition of nanosilica sol. At the same time, it also means that the early performance of HBSAC cement mortar almost comes from the hydration of anhydrous calcium sulphoaluminate. Moreover, with the increase in nanosilica sol content, the mass loss rate of hydrated calcium sulphoaluminate 
(AFt) increases, which also means that nanosilica sol can promote the hydration reaction of $\mathrm{C}_{4} \mathrm{~A}_{3} \overline{\mathrm{S}}$. This phenomenon is basically consistent with the XRD experimental results.
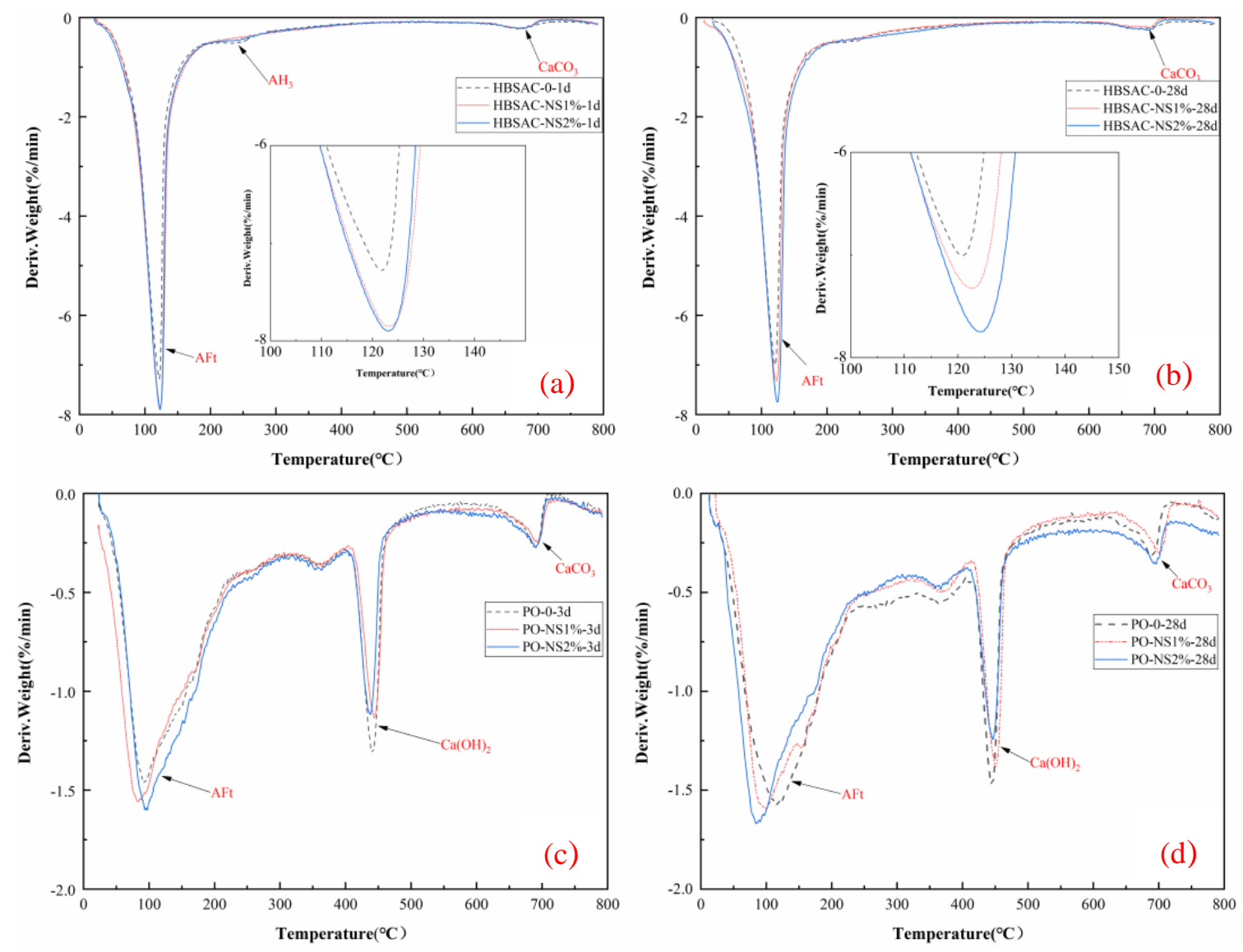

Figure 6. DTG curves of the series cement hydration products at different curing ages: (a) HBSAC cement at 1 day; (b) HBSAC cement at 28 days; (c) P.O 42.5 cement at 1 day; (d) P.O 42.5 cement at 28 days.

The dehydration decomposition temperature of calcium silicate hydrate (C-S-H), one of the hydration products of P.O 42.5 cement, is generally $100-400{ }^{\circ} \mathrm{C}$. From Figure $6 \mathrm{c}, \mathrm{d}$, it can be concluded that the content of calcium hydroxide $\left(\mathrm{Ca}(\mathrm{OH})_{2}\right)$ decreases with the increase in nanosilica content, which may be caused by the "secondary hydration reaction" between nanosilica and calcium hydroxide $\left(\mathrm{Ca}(\mathrm{OH})_{2}\right)$. This phenomenon is consistent with the above XRD analysis conclusion. There is a dehydration decomposition peak in the range of $700-800{ }^{\circ} \mathrm{C}$, and the product may be calcite, which is probably caused by the carbonization of calcium hydroxide $\left(\mathrm{Ca}(\mathrm{OH})_{2}\right)$ by protective gas during the test [37].

\subsection{SEM Micromorphology}

Figure 7 shows the SEM micromorphology of HBSAC cement to which nanosilica sol is added. The hydration products of high-belite sulphoaluminate cement HBSAC are mainly rod-shaped ettringite (AFt).

The microscopic morphology of the ettringite phase, the main hydration product of HBSAC cement, is needle-rod shaped. Compared with the control group, it can be seen that the acicular ettringite in HBSAC cement added with nanosilica sol becomes coarse. Ettringite overlaps alternately to form a skeleton, which is filled with gel phases such as aluminum glue to fill gaps and cementation, thus making the hardened cement paste denser $[38,39]$. The reason for this phenomenon may be that the crystal nucleus of nanomaterials plays a role, which is also strong proof that nanosilica promotes cement hydration. 

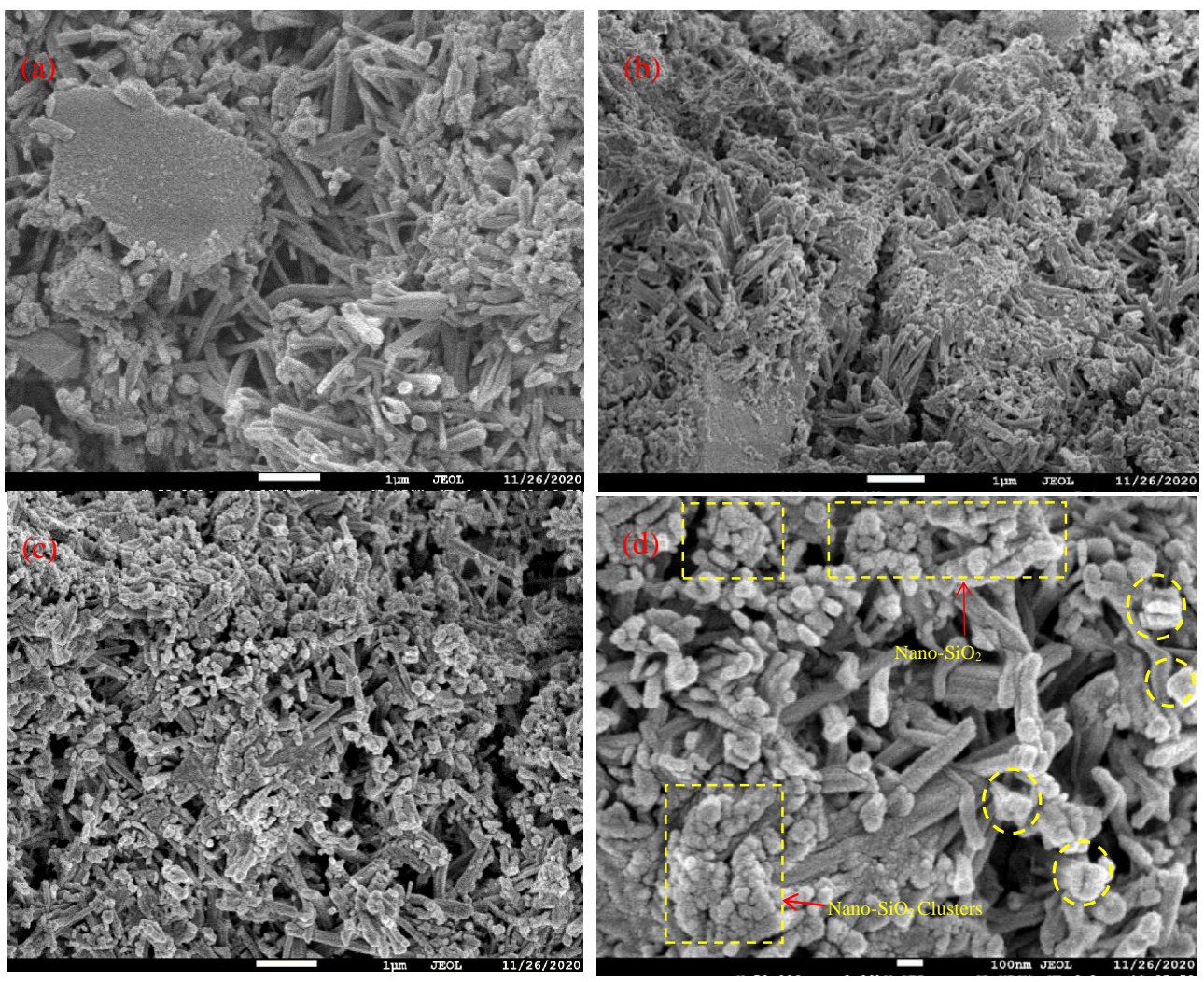

Figure 7. SEM micromorphology of the HBSAC cement hydration products with different contents of nanosilica sol: (a) nanosilica sol content $2 \%$ at 1 day; (b) nanosilica sol content 0 at 1 day; (c) nanosilica sol content $2 \%$ at 28 days; (d) nanosilica sol content $2 \%$ at 28 days.

From Figure 7c,d, it can be seen that the nanosilica is not uniformly distributed in the cement paste. Nanosilica has great surface energy, and it will agglomerate when mixed with cement particles. Some of the nanosilica particles are adsorbed around the cement particles, and only some of the nanosilica particles are evenly dispersed in the paste. The distribution of silica in cement paste is shown in Figure 1. These agglomerates may form weak areas such as pores inside the paste, which can become an incentive to weaken the performance of concrete and mortar [40].

Figure 8 shows the SEM micromorphology of P.O 42.5 cement paste with nanosilica sol. From Figure 8a,b, it can be seen that the mechanism of nanosilica sol in P.O 42.5 cement is different from that in HBSAC. Similarly, the nanosilica sol will be adsorbed around the cement particles when the mortar is mixed and act as a nucleus site when the cement particles are hydrated, promoting the hydration of the cement. At the same time, the nanosilica dispersed around the cement hydration product $\mathrm{Ca}(\mathrm{OH})_{2}$ will react to form calcium silicate hydrate sol $(\mathrm{C}-\mathrm{S}-\mathrm{H})$. This reaction is undoubtedly beneficial to the performance of mortar and concrete. Hydrated calcium silicate sol $(\mathrm{C}-\mathrm{S}-\mathrm{H})$ can fill the pores inside the paste, making the paste denser. 

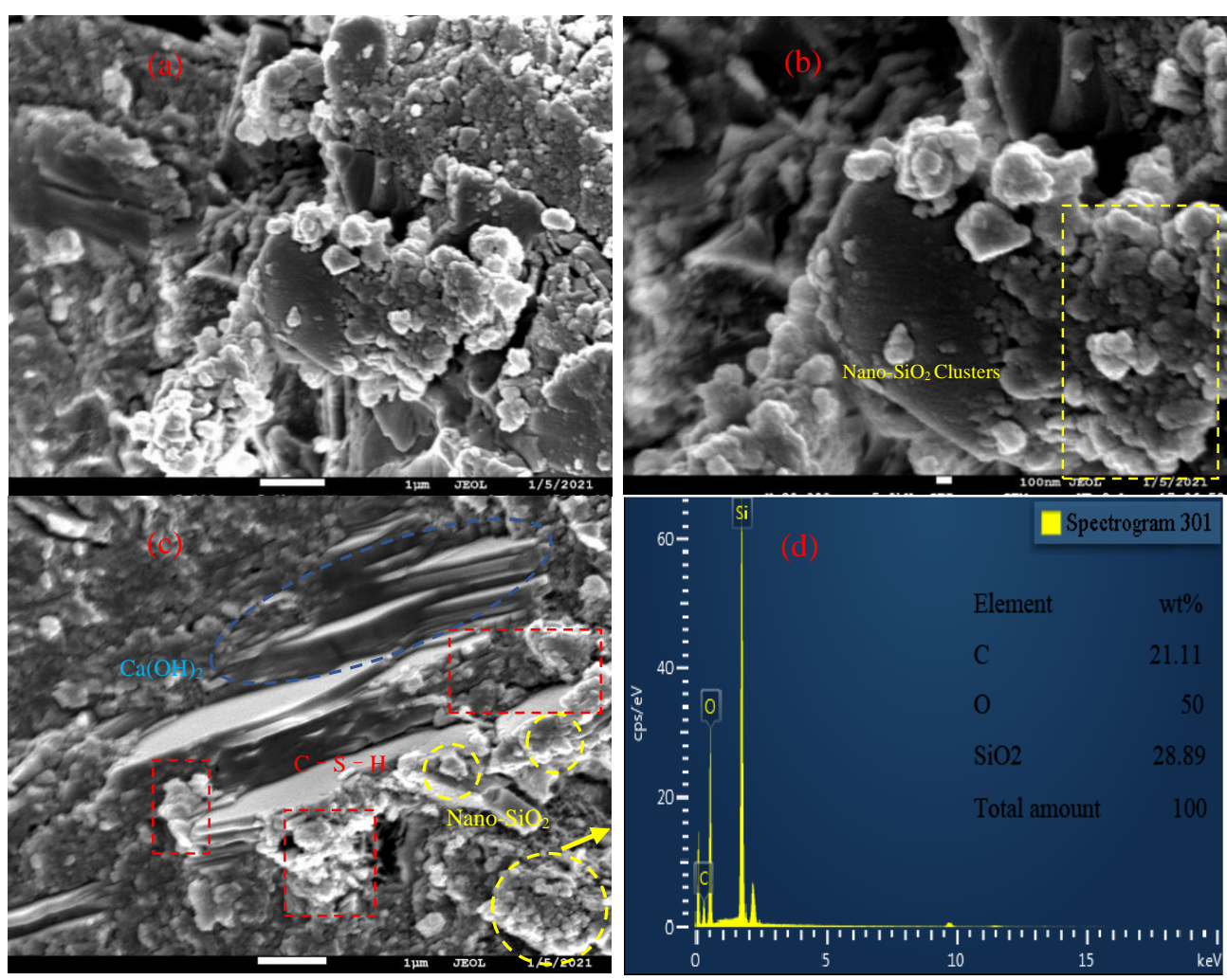

Figure 8. SEM micromorphology of the P.O 42.5 cement hydration products at curing ages of 28 days: (a-c) "secondary hydration reaction" between nanosilica particles and calcium hydroxide; (d) EDS image of nanosilica sol clusters (the test points are taken from $(\mathbf{c})$ ).

\subsection{Workability and Mechanical Strength \\ 3.4.1. Workability}

Figure 9 shows the setting time of a cement paste with different contents of nanosilica sol. When the content of nanosilica sol is $1 \%$ and $2 \%$, the initial setting time of P.O 42.5 cement is shortened by $2 \mathrm{~min}$ and $4 \mathrm{~min}$, respectively, and the final setting time is shortened by $3 \mathrm{~min}$ and $7 \mathrm{~min}$, respectively. Similarly, compared with the control group, when the content of nanosilica sol is $1 \%$ and $2 \%$, the initial setting time of HBSAC cement is shortened by $6 \mathrm{~min}$ and $13 \mathrm{~min}$, respectively, and the final setting time is shortened by $21 \mathrm{~min}$ and $34 \mathrm{~min}$, respectively. The promoting effect of nanosilica sol on cement hydration can also be reflected in cement setting time. The experimental results show that the addition of nanosilica sol reduces the initial setting time and final setting time of the two kinds of cement to a certain extent, and this phenomenon becomes more obvious with the increase in nanosilica content. This change trend is consistent with the results of hydration heat analysis, which is strong proof that nanosilica sol can promote cement hydration. 

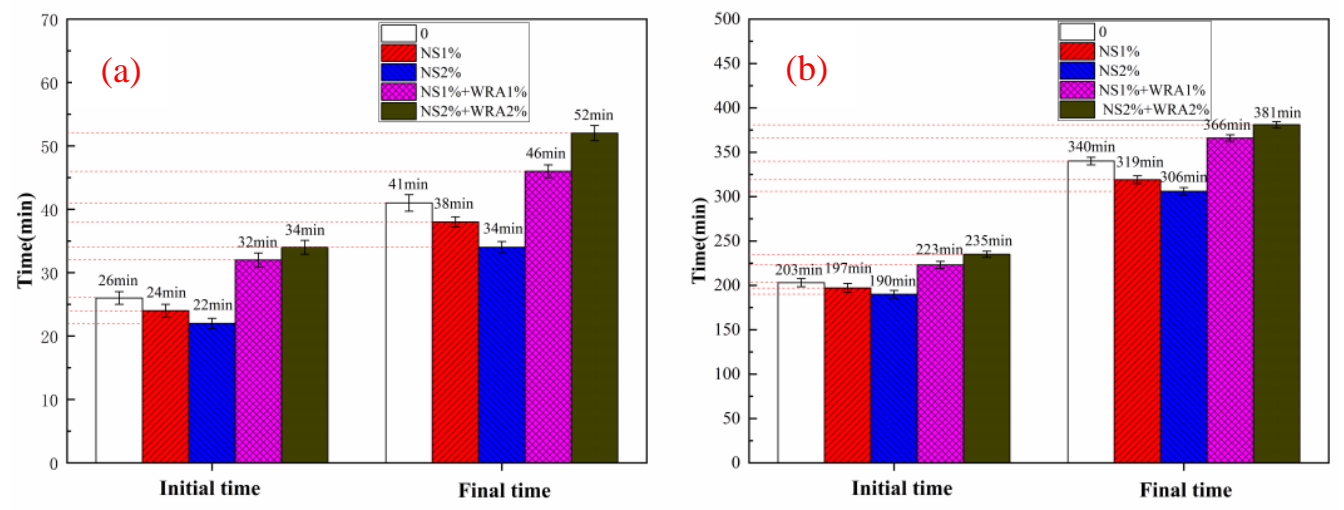

Figure 9. Setting time of different cements: (a) HBSAC cement; (b) P.O 42.5 cement.

\subsubsection{Mechanical Strength}

The strength test method of cement mortar refers to GB/T 17671-2020, “Test Method for Strength of Cement Mortar". In the experiment, the experimental group without nanosilica was set as the control group.

The test results show that the influence of nanosilica sol on the strength of HBSAC cement and P.O 42.5 cement is different. Firstly, the influence of nanosilica sol on the strength of HBSAC cement is related to its curing age. In the early hydration stage of HBSAC cement, adding nanometer silica sol can effectively improve the strength of cement mortar. When the curing age was more than $3 \mathrm{~h}$, this promotion effect began to decrease gradually Secondly, the content of nanosilica sol has the best content for the strength of cement mortar, which is about $1 \%$. The main hydration reaction of HBSAC cement is shown in Equation (2), and the hydration reaction is carried out rapidly and can be completed quickly within $3 \mathrm{~h}$. From the XRD analysis of the hydration product, it can be concluded that there is almost no $\mathrm{Ca}(\mathrm{OH})_{2}$ in the hydration product, which means that the pozzolanic activity of nanosilica cannot be exerted during the hydration reaction of HBSAC cement paste. As shown in Figures 10 and 8c, nanosilica clusters form pores in the paste, and the pores will increase with the increase in nanosilica sol content. These pores form a deteriorated interface, which will adversely affect the strength of mortar.
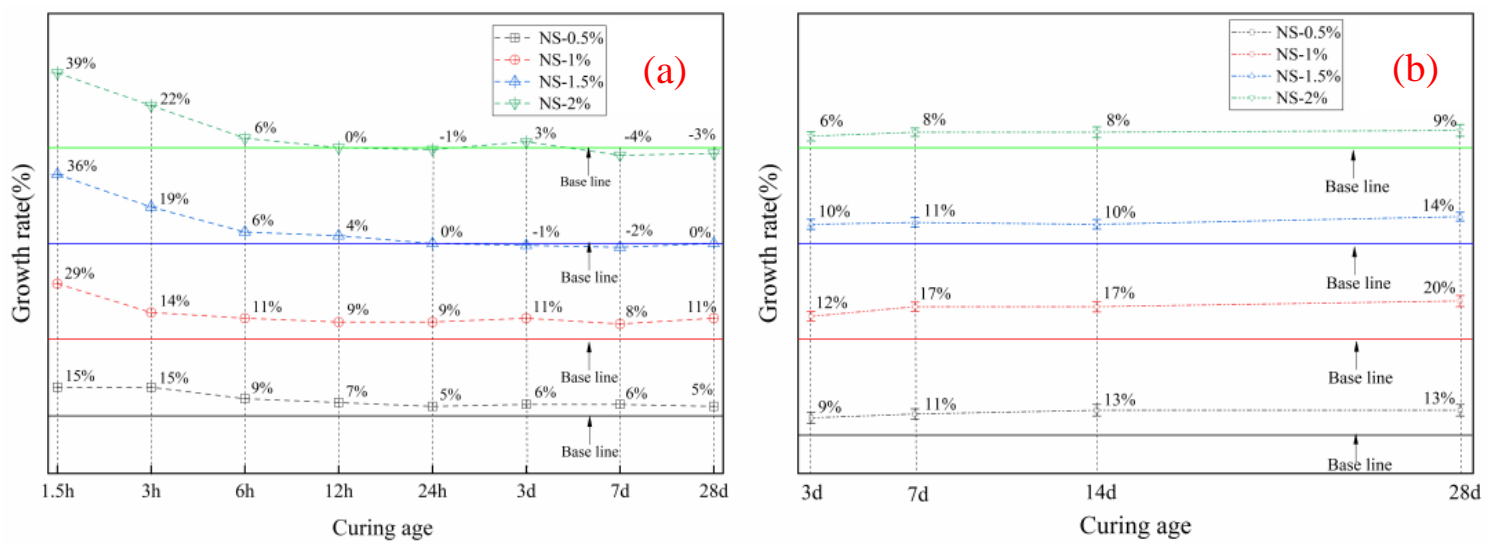

Figure 10. Growth rate of the cement mortar compressive strength: (a) HBSAC cement; (b) P.O 42.5 cement.

The promotion effect of nanosilica sol on the strength of P.O 42.5 cement gradually increases with the increase in curing age. Secondly, with the increase in the content of nanosilica sol, the promotion effect shows an increasing trend at first and then a decreasing trend, and the best content is about $1 \%$. As shown in Figure $8 \mathrm{c}$, a large amount of $\mathrm{Ca}(\mathrm{OH})_{2}$ generated by the hydration reaction of ordinary Portland cement will rapidly undergo a hydration reaction with nanosilica adsorbed around, and the generated hydrated calcium 
silicate gel (C-S-H) can effectively fill the pores inside the paste, making the paste denser, thus effectively promoting the strength increase of mortar.

\subsection{Porosity}

Figure 11 shows the porosity of cement paste with different amounts of nanosilica sol. The test results show that the proper content of nanosilica sol can effectively reduce the porosity of mortar, but too-high content will lead to an increase in porosity, which is applicable to both HBSAC cement and P.O 42.5 cement. The research results of Quercia [41] show that a part of nanosilica particles mixed in fresh mortar will be adsorbed around cement particles and water-reducing agent particles. After the cement paste is hardened, nanosilica particles can effectively fill the pores in the cement paste, which is exactly the embodiment of nanosilica "microaggregate effect". The data show that the best content of nanosilica sol is about $1 \%$. However, nanosilica usually exists in the form of clusters, which will leave pores in the cement paste after hardening. This phenomenon can also explain why a large amount of nanosilica sol will increase the porosity of the cement paste.
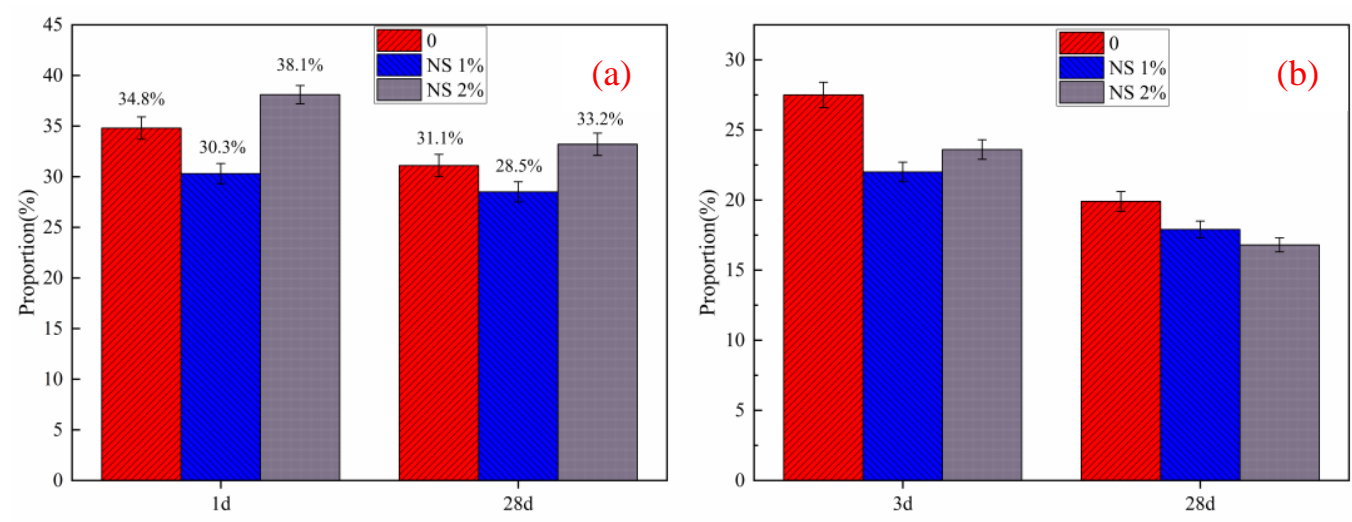

Figure 11. Porosity of cement mortar: (a) HBSAC cement; (b) P.O 42.5 cement.

Figure 12 shows the pore size distribution of cement paste. The research results of Metha [42] show that the pores in the cement paste can be divided into four categories according to the pore diameter: less than $4.5 \mathrm{~mm}, 4.5-50 \mathrm{~mm}, 50-100 \mathrm{~mm}$ and greater than $100 \mathrm{~mm}$, of which only the pores greater than $100 \mathrm{~mm}$ are called harmful pores. Too many harmful holes will adversely affect the strength and permeability of mortar. As shown in Figure 12, doping nanometer silica sol can effectively optimize the pore size distribution inside the mortar paste, but too high a doping amount will lead to an increase in harmful pores, and the optimal doping amount of nanometer silica is about $1 \%$. With the increase in curing age, nanosilica can optimize the pore structure in paste, which makes the number of harmful pores drop sharply. In addition, there is an interesting phenomenon when adding the same amount of nanosilica, the harmful pores of HBSAC cement are more than those of P.O 42.5 cement. This phenomenon may be caused by the reaction between nanosilica clusters and calcium hydroxide to reduce the number of harmful pores in cement mortar, while HBSAC cement does not have this reaction characteristic. 

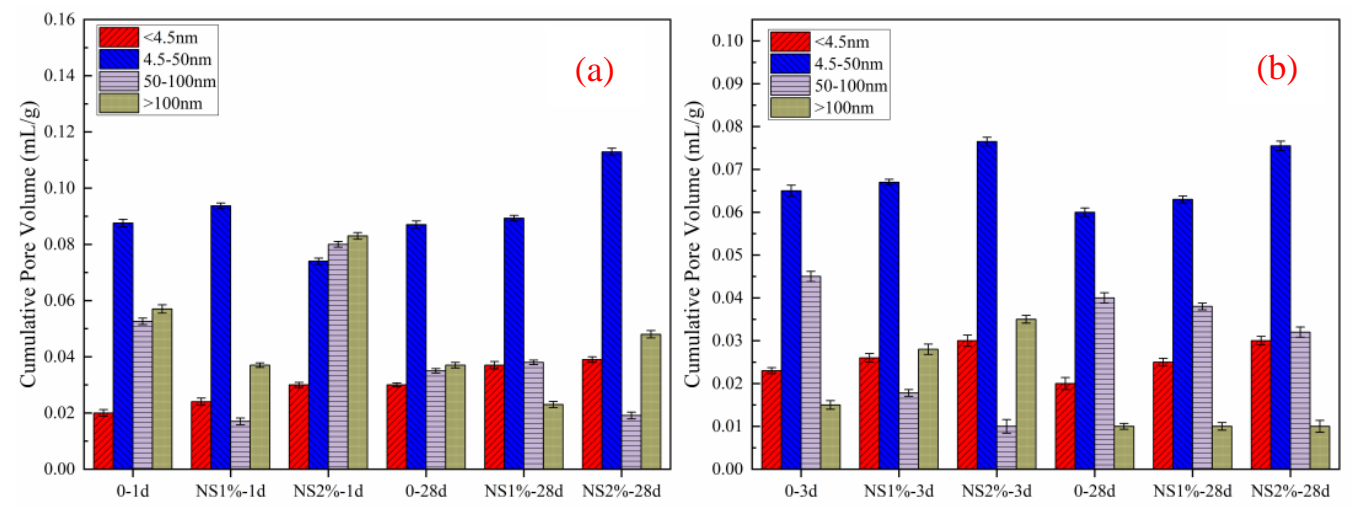

Figure 12. Pore size distribution of cement paste: (a) HBSAC cement; (b) P.O 42.5 cement.

\subsection{Chloride Penetration Resistance}

Figure 13 shows the chloride penetration resistance of mortar with different contents of nanosilica sol. Chloride penetration resistance of mortar is one of the most important performance indexes of mortar and concrete because it directly determines whether the steel bars in concrete can be effectively protected. The test results show that at the early age of mortar, the content of nanosilica is about $1 \%$, which contributes the most to the chloride penetration resistance of mortar. However, when the content of nanosilica sol reaches $2 \%$, it will adversely affect the chloride penetration resistance of mortar, which is applicable to both HBSAC cement and P.O 42.5 cement. This change trend is consistent with the change law of the porosity of cement mortar. This phenomenon may be due to the filling effect and the secondary hydration reaction of nanosilica, which leads to a reduction in harmful pores in cement paste and makes the paste denser.
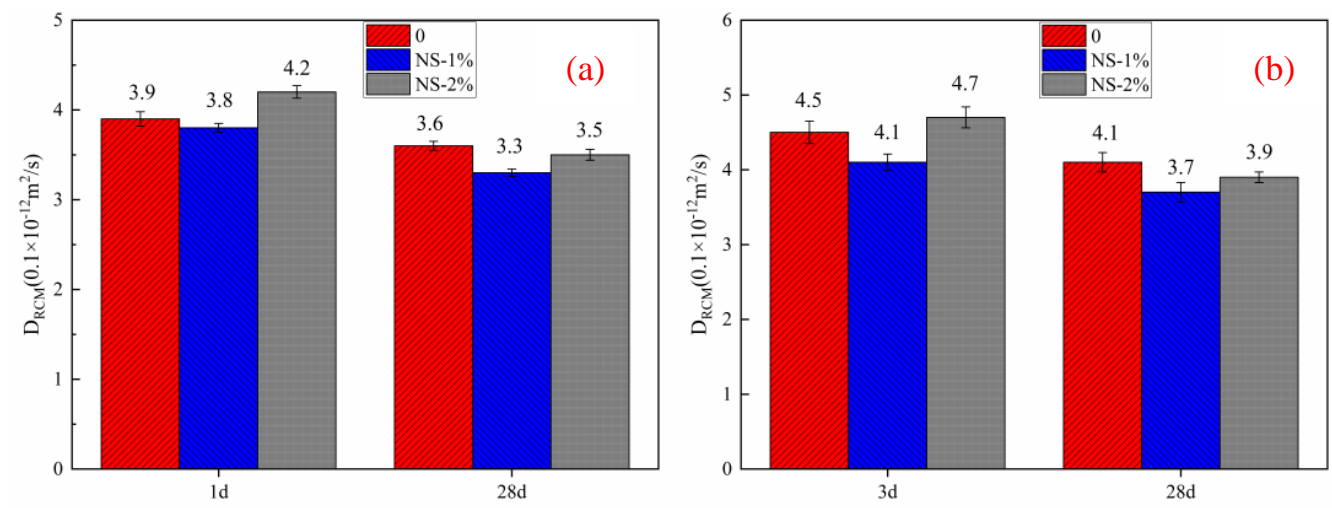

Figure 13. Chloride penetration resistance of cement mortar: (a) HBSAC cement; (b) P.O 42.5 cement.

\section{Conclusions}

In this study, hydration heat analysis, SEM observation and XRD analysis were used to study the changes of nanosilica sol on the hydration process and micromorphology of HBSAC cement and P.O 42.5 cement, mechanical strength, porosity, chloride penetration resistance and other performance indicators of mortar, and the following results and conclusions are obtained.

1. Adding nanometer silica sol can not only accelerate the hydration speed of cement but also promote the hydration degree of cement, and this phenomenon is applicable to both kinds of cement. The greater the content of nanosilica sol, the more obvious the promotion effect. The promotion effect of nanosilica sol on the cumulative heat of hydration of HBSAC cement reached the peak at about $20 \mathrm{~min}$, and that of P.O 42.5 cement reached the peak at about $20 \mathrm{~min}$.

2. From the analysis of cement hydration products, it is concluded that for high-belite sulphoaluminate cement (HBSAC), nanosilica sol can effectively promote the hydra- 
tion of anhydrous calcium sulphoaluminate, but the hydration promotion effect on $\beta-C_{2} S$ is weak. For ordinary Portland cement, nanosilica sol can effectively promote the hydration process of $\mathrm{C}_{3} \mathrm{~S}$, and the content of calcium hydroxide $(\mathrm{CH})$ in hydration products decreases with the increase in nanosilica sol content, which may be due to the "secondary hydration reaction" between calcium hydroxide $(\mathrm{CH})$ and nanosilica.

3. SEM observation shows that nanosilica sol can accelerate the hydration rate of HBSAC cement, and the hydration products grow faster. At the same time, nanosilica sol can react with calcium hydroxide, which the P.O 42.5 cement hydration reaction produces, to form hydrated calcium silicate gel. However, the agglomeration of nanosilica particles in the cement paste can also be observed, which may adversely affect the pore structure and permeability resistance of the mortar.

4. MIP analysis and chloride penetration resistance showed that nanosilica sol clusters have a negative effect on the pore structure of mortar, thus affecting the permeability resistance of mortar. The test results showed that when the content of nanosilica sol is greater than $1 \%$, the harmful pores in mortar will increase, which will damage the permeability resistance and strength performance of mortar. At the 28-day age of mortar, the $\mathrm{D}_{\mathrm{RCM}}$ value of HBSAC cement mortar decreased by $7.7 \%, 13.2 \%$ and $16.7 \%$, respectively when the content of nanosilica sol was $0,1 \%$ and $2 \%$. The $\mathrm{D}_{\mathrm{RCM}}$ value of P.O 42.5 cement mortar decreased by $8.9 \%, 9.8 \%$ and $17 \%$ when the content of nanosilica sol was $0,1 \%$ and $2 \%$, respectively. This phenomenon may be due to the improvement of harmful pores of mortar by nanosilica sol particles.

Author Contributions: Investigation, methodology, formal analysis, data course, and writingoriginal draft preparation, H.L.; project administration, conception, and supervision, Q.L.; writingreview and editing and software, D.S.; resources, visualization, and funding acquisition, G.Y.; validation, L.W. All authors have read and agreed to the published version of the manuscript.

Funding: Project Numbers 52078261, 51978353, 51878366, and 51808310 from the National Natural Science Foundation of China and Project Numbers ZR2020ME036 and ZR2019PEE007 from the Natural Science Foundation of Shandong Province.

Institutional Review Board Statement: Not applicable.

Informed Consent Statement: Not applicable.

Acknowledgments: The authors gratefully acknowledge the financial support of Project Numbers 52078261, 51978353, 51878366, and 51808310 from the National Natural Science Foundation of China and Project Numbers ZR2020ME036 and ZR2019PEE007 from the Natural Science Foundation of Shandong Province.

Conflicts of Interest: The authors declare no conflict of interest.

\author{
Abbreviations \\ The following abbreviations are used in this manuscript: \\ HBSAC High-belite sulphoaluminate cement \\ P.O 42.5 Ordinary Portland cement (42.5 grade) \\ $\mathrm{CH} \quad \mathrm{Ca}(\mathrm{OH})_{2}$ \\ AFt $\quad 3 \mathrm{CaO} \cdot \mathrm{Al}_{2} \mathrm{O}_{3} \cdot 3 \mathrm{CaSO}_{4} \cdot 32 \mathrm{H}_{2} \mathrm{O}$ \\ $\beta-\mathrm{C}_{2} \mathrm{~S} \quad 2 \mathrm{CaO} \cdot \mathrm{SiO}_{2}$ \\ $\mathrm{C}_{3} \mathrm{~S} \quad 3 \mathrm{CaO} \cdot \mathrm{SiO}_{2}$ \\ $\mathrm{C}_{4} \mathrm{~A}_{3} \overline{\mathrm{S}} \quad 3 \mathrm{CaO} \cdot 3 \mathrm{Al}_{2} \mathrm{O}_{3} \cdot \mathrm{CaSO}_{4}$
}




\section{References}

1. Ferraris, C.F.; Obla, K.H.; Hill, R. The influence of mineral admixtures on the rheology of cement paste and concrete. Cem. Concr. Res. 2001, 31, 245-255. [CrossRef]

2. Flores, Y.C.; Cordeiro, G.C.; Toledo Filho, R.D.; Tavares, L.M. Performance of Portland cement pastes containing nano-silica and different types of silica. Constr. Build. Mater. 2017, 146, 524-530. [CrossRef]

3. Flores-Vivian, I.; Pradoto, R.G.K.; Moini, M.; Kozhukhova, M.; Potapov, V.; Sobolev, K. The effect of SiO2 nanoparticles derived from hydrothermal solutions on the performance of Portland cement based materials. Front. Struc. Civ. Eng. 2017, 11, 436-445. [CrossRef]

4. Kawashima, S.; Hou, P.; Corr, D.J.; Shah, S.P. Modification of cement-based materials with nanoparticles. Cem. Concr Compos. 2013, 36, 8-15. [CrossRef]

5. Li, W.; Huang, Z.; Cao, F.; Sun, Z.; Shah, S.P. Effects of nano-silica and nano-limestone on flowability and mechanical properties of ultra-high-performance concrete matrix. Constr. Build. Mater. 2015, 95, 366-374. [CrossRef]

6. Li, Y.; Bao, J.; Guo, Y. The relationship between autogenous shrinkage and pore structure of cement paste with mineral admixtures. Constr. Build. Mater. 2010, 24, 1855-1860. [CrossRef]

7. Liu, B.; Luo, G.; Xie, Y. Effect of curing conditions on the permeability of concrete with high volume mineral admixtures. Constr Build. Mater. 2018, 167, 359-371. [CrossRef]

8. Ma, B.; Wang, J.; Tan, H.; Li, X.; Cai, L.; Zhou, Y.; Chu, Z. Utilization of waste marble powder in cement-based materials by incorporating nano silica. Constr. Build. Mater. 2019, 211, 139-149. [CrossRef]

9. Qin, L.; Gao, X.; Chen, T. Influence of mineral admixtures on carbonation curing of cement paste. Constr. Build. Mater. 2019, 212, 653-662. [CrossRef]

10. Said, A.M.; Zeidan, M.S.; Bassuoni, M.T.; Tian, Y. Properties of concrete incorporating nano-silica. Constr. Build. Mater. 2012, 36, 838-844. [CrossRef]

11. Sulapha, P.; Wong, S.F.; Wee, T.H.; Swaddiwudhipong, S. Carbonation of concrete containing mineral admixtures. J. Mater. Civil. Eng. 2003, 15, 134-143. [CrossRef]

12. Uysal, M.; Sumer, M. Performance of self-compacting concrete containing different mineral admixtures. Constr. Build. Mater. 2011, 25, 4112-4120. [CrossRef]

13. Wang, J.; Du, P.; Zhou, Z.; Xu, D.; Xie, N.; Cheng, X. Effect of nano-silica on hydration, microstructure of alkali-activated slag. Constr. Build. Mater. 2019, 220, 110-118. [CrossRef]

14. Yu, R.; Spiesz, P.; Brouwers, H.J.H. Effect of nano-silica on the hydration and microstructure development of ultra-high performance concrete (UHPC) with a low binder amount. Constr. Build. Mater. 2014, 65, 140-150. [CrossRef]

15. Reches, Y.; Thomson, K.; Helbing, M.; Kosson, D.S.; Sanchez, F. Agglomeration and reactivity of nanoparticles of $\mathrm{SiO}_{2}$, $\mathrm{TiO}_{2}$ $\mathrm{Al}_{2} \mathrm{O}_{3}, \mathrm{Fe}_{2} \mathrm{O}_{3}$, and clays in cement pastes and effects on compressive strength at ambient and elevated temperatures. Constr. Build. Mater. 2018, 167, 860-873. [CrossRef]

16. Hou, P.; Wang, K.; Qian, J.; Kawashima, S.; Kong, D.; Shah, S.P. Effects of colloidal nanoSiO2 on fly ash hydration. Cem. Concr. Compos. 2012, 34, 1095-1103. [CrossRef]

17. Amiri, A.; Øye, G.; Sjöblom, J. Influence of $\mathrm{pH}$, high salinity and particle concentration on stability and rheological properties of aqueous suspensions of fumed silica. Colloid. Surf. A 2009, 349, 43-54. [CrossRef]

18. Kirby, G.H.; Lewis, J.A. Comb polymer architecture effects on rheological property evolution of concentrated cement suspensions. J. Am. Ceram. Soc. 2004, 87, 1643-1652. [CrossRef]

19. Ghafari, E.; Costa, H.; Júlio, E.; Portugal, A.; Durães, L. The effect of nanosilica addition on flowability, strength and transport properties of ultra high performance concrete. Mater. Des. 2014, 59, 1-9. [CrossRef]

20. Hou, P.K.; Kawashima, S.; Wang, K.J.; Corr, D.J.; Qian, J.S.; Shah, S.P. Effects of colloidal nanosilica on rheological and mechanical properties of fly ash-cement mortar. Cem. Concr. Compos. 2013, 35, 12-22. [CrossRef]

21. Li, H.; Xiao, H.-G.; Yuan, J.; Ou, J. Microstructure of cement mortar with nanoparticles. Compos. Part B Eng. 2004, 35, 185-189. [CrossRef]

22. Rong, Z.; Sun, W.; Xiao, H.; Jiang, G. Effects of nano-SiO2 particles on the mechanical and microstructural properties of ultra-high performance cementitious composites. Cement Concr. Compos. 2015, 56, 25-31. [CrossRef]

23. Thomas, J.; Jennings, H.M.; Chen, J.J. Influence of nucleation seeding on the hydration mechanisms of tricalcium silicate and cement. J. Phys. Chem. 2009, 113, 4327-4334. [CrossRef]

24. Kong, D.; Su, Y.; Du, X.; Yang, Y.; Wei, S.; Shah, S.P. Influence of nano-silica agglomeration on fresh properties of cement pastes. Constr. Build. Mater. 2013, 43, 557-562. [CrossRef]

25. Berra, M.; Carassiti, F.; Mangialardi, T.; Paolini, A.; Sebastiani, M. Effects of nanosilica addition on workability and compressive strength of Portland cement pastes. Constr. Build. Mater. 2012, 35, 666-675. [CrossRef]

26. Zhang, X.; Yang, H.; Yang, Q.; Du, X.; Li, C.; Cheng, X. Effects of particle size of colloidal nanosilica on hydration of Portland cement at early age. Adv. Mech. Eng. 2019, 11, 1687814019828948. [CrossRef]

27. Ghasemi, A.M.R.; Parhizkar, T.; Ramezanianpour, A.A. Influence of colloidal nano-SiO $\mathrm{O}_{2}$ addition as silica fume replacement material in properties of concrete. In Proceedings of the Second International Conference on Sustainable Construction Materials and Technologies, Ancona, Italy, 28-30 June 2010; pp. 28-30. 
28. Kong, D.; Corr, D.; Hou, P.; Yang, Y.; Shah, S.P. Influence of colloidal silica sol on fresh properties of cement paste as compared to nano-silica powder with agglomerates in micron-scale. Cem. Conc. Compos. 2015, 63, 30-41. [CrossRef]

29. Kong, D.; Pan, H.; Wang, L.; Corr, D.; Yang, Y.; Shah, S.P.; Sheng, J. Effect and mechanism of colloidal silica sol on properties and microstructure of the hardened cement-based materials as compared to nano-silica powder with agglomerates in micron-scale. Cem. Conc. Compos. 2019, 98, 137-149. [CrossRef]

30. Liu, C.; Luo, J.; Li, Q.; Gao, S.; Su, D.; Zhang, J.; Chen, S. Calcination of green high-belite sulphoaluminate cement (GHSC) and performance optimizations of GHSC-based foamed concrete. Mater. Des. 2019, 182, 107986. [CrossRef]

31. Su, D.; Yue, G.; Li, Q.; Guo, Y.; Gao, S.; Wang, L. Research on the preparation and properties of high belite sulphoaluminate cement (HBSAC) based on various industrial solid wastes. Materials 2019, 12, 1510. [CrossRef]

32. Wang, X.; Gong, C.; Lei, J.; Dai, J.; Lu, L.; Cheng, X. Effect of silica fume and nano-silica on hydration behavior and mechanism of high sulfate resistance Portland cement. Constr. Build. Mater. 2021, 279, 122481. [CrossRef]

33. Aly, M.; Hashmi, M.; Olabi, A.G.; Messeiry, M.; Abadir, E.; Hussain, A. Effect of colloidal nano-silica on the mechanical and physical behaviour of waste-glass cement mortar. Mater. Des. 2012, 33, 127-135. [CrossRef]

34. Wu, Y.; Li, Q.; Li, G.; Tang, S.; Niu, M.; Wu, Y. Effect of naphthalene-based superplasticizer and polycarboxylic acid superplasticizer on the properties of sulfoaluminate cement. Materials 2021, 14, 662. [CrossRef]

35. Memon, S.A.; Shah, S.F.A.; Khushnood, R.A.; Baloch, W.L. Durability of sustainable concrete subjected to elevated temperature-A review. Constr. Build. Mater. 2019, 199, 435-455. [CrossRef]

36. Sadique, M.; Al-Nageim, H.; Atherton, W.; Seton, L.; Dempster, N. Analytical investigation of hydration mechanism of a non-Portland binder with waste paper sludge ash. Constr. Build. Mater. 2019, 211, 80-87. [CrossRef]

37. Rostami, V.; Shao, Y.; Boyd, A.J.; He, Z. Microstructure of cement paste subject to early carbonation curing. Cem. Conc. Res. 2012, 42, 186-193. [CrossRef]

38. Lv, S.; Liu, J.; Sun, T.; Ma, Y.; Zhou, Q. Effect of GO nanosheets on shapes of cement hydration crystals and their formation process. Constr. Build. Mater. 2014, 64, 231-239. [CrossRef]

39. Zhang, J.; Sun, Y. Experimental and mechanism study of a polymer foaming grouting material for reinforcing broken coal mass. KSCE J. Civ. Eng. 2019, 23, 346-355. [CrossRef]

40. Kong, D.; Du, X.; Wei, S.; Zhang, H.; Yang, Y.; Shah, S.P. Influence of nano-silica agglomeration on microstructure and properties of the hardened cement-based materials. Constr. Build. Mater. 2012, 37, 707-715. [CrossRef]

41. Quercia, G.; Hüsken, G.; Brouwers, H.J.H. Water demand of amorphous nano silica and its impact on the workability of cement paste. Cem. Concr. Res. 2012, 42, 344-357. [CrossRef]

42. Mehta, P.K.; Monteiro, P.J.M. Concrete: Microstructure, Properties, and Materials; McGraw-Hill Education: New York, NY, USA, 2014; pp. 23-28. 